\title{
Role of IT Management and the Dynamics Behind IT Business Value Creation - A Longitudinal Assessment
}

\author{
Tomi Dahlberg \\ Turku School of Economics at the University of Turku \\ $\&$ Aalto University School of Business, Finland \\ tomi.dahlberg@utu.fi
}

\author{
Hannu Kivijärvi \\ Aalto University School of Business \\ P.O. Box 21220, 00076 Aalto, Finland \\ hannu.kivijarvi@aalto.fi
}

\begin{abstract}
In this study, we investigated how "good" IT management with its linkages to other factors influence IT business value (ITBV). First, we identified potential model constructs, then hypothesized about the relationships between the constructs and finally integrated the hypotheses into a research model. We empirically probed the hypotheses and our dynamic research model. We used survey data of 642 responses collected with annual surveys from $\mathrm{CxOs}$ during the years 2013, 2014 and 2015. Empirical results confirmed that the research model factors affected IT business value positively. The perceived importance of IT was discovered to be an antecedent to IT management. Both these constructs were detected to influence IT business value indirectly through the other model constructs. As a feedback, the perceived importance of IT depends strongly on IT business value.
\end{abstract}

\section{Introduction}

During the recent decades the relationship between IT and business value has been investigated extensively. Some researchers have claimed that IT does not provide value to organizations [9], or fails to impact competitive factors positively [44, 43]. Yet, most practitioners and researchers agree with the statement that, on average, IT deployment is able to improve organizational performance and competitiveness [7]. Another typical proposition is that "good" IT management is needed to deploy IT successfully, to achieve IT business value and IS success, and to improve performance [33, 42, 48, 55].

The proposition that good IT management provides benefits to an organization appears intuitively sound. IT management can be regarded as a specific management context. When IT is used growingly outside of the traditional IT usage areas and/or managed more by other than the IT function, it is logical to propose that good IT management is increasingly important to organizations. But to what extent are such propositions valid and true?

Our aim is to investigate how IT management influences IT business value directly and indirectly through other factors investigated in earlier research. We also examine whether perceptions about the importance of IT impact the IT management factor as an anteceding factor. In addition to factors often considered in earlier studies, we include the fit factor [15]. Fit is seen as the suitability of something for a certain purpose or context [15]. Our research idea is to examine how changes in the economic environment of an organization influence IT

URI: http://hdl.handle.net/10125/50530

ISBN: 978-0-9981331-1-9

(CC BY-NC-ND 4.0) business value perceptions. According to our research idea, an organization "fits" to its economic environment initiated and guided by (IT) management. That is, adaptation/fit activities execute and implement IT management's objectives, one of which is to adapt/fit to the organization's economic environment. That may then impact the business value of IT. Although fit is a muchinvestigated theoretical concept, it has received limited attention in IT business value research.

We used survey data collected from business and IT executives with three annual surveys during the years 2013, 2014 and 2015 to test our hypotheses and research model. Cumulatively 642 responses were used. The context of the surveys provided additional motivation for the research. The country of the survey (Finland) experienced an economic recession during the mentioned years. During a recession, there could be pressures to cut IT costs, to postpone IT investments, and to limit IT development in order to improve an organization's costefficiency. There could also be needs to create new businesses, to consolidate IT assets, to improve data quality, to train users, and to develop IT competencies. Cumulatively both types of activities could make the organization more fit to deal with economic cycles [11]. Reactions to an economic recession probably differ. Some organizations may continue IT investments and IT spending by avoiding unplanned and/or ad-hoc investment postponements and cost run-downs. They might also utilize the recession to improve the efficiency of their IT with focused IT development activities, such as data quality improvement or IT asset consolidation. These organizations may thus reach better fit to the environment, which may result in higher IT business value in the long run, compared to organizations, which take more hasty actions in cutting down IT development.

The generic research problem of our study is to investigate factors that create IT business value. From the generic research problem, we formulate the following specific research questions for this study:

1. What is the significance of IT management as an IT business value enabling factor?

2. What other factors influence IT business value, especially how fit influences IT business value creation alone and combined with IT management?

To answer these research questions we first review the theoretical background of our study. We then explicate our research model with related hypotheses and discuss the methods of empirical data collection and analysis. The results of statistical model and hypotheses testing are presented in Section 4. The paper ends with a discussion on the theoretical and empirical findings of our study, and on conclusions.

$\mathrm{HI}$ C S S
Page 5136 


\section{Theoretical background}

The research tradition, on how IT deployment and IT management provide value to organizations, is known as IT business value (ITBV) research [e.g. 33, 48]. Concepts investigated include business-IT alignment [e.g. 29], IT management and IT governance [e.g. 16], technology strategies [e.g. 19], the execution of IT investments and projects [e.g. 32], data and information management [e.g. 51], enterprise architecture and integrations [e.g. 54], and IT capabilities [e.g. 40]. Several measures have been crafted to capture IT/IS business value/success [see e.g. 42]. The generic presumption is that "good" IT management over IT capabilities, business-IT alignment and other abovementioned factors influence positively IT business value. Both Kohli and Gover [33] and Schryen [48] still conclude in their state-of the art articles that research has left many issues unanswered. For example, Schryen wrote in 2013: "While the vast majority of research papers on IS business value find empirical evidence in favor of both the operational and strategic relevance of IS, the fundamental question of the causal relationship ... remains partly unexplained." [48, p. 139]

Against this research gap, we discuss below the key concepts of our study and potential relations - causal relationships - between them. Attention is also paid to the dynamic relations between the concepts. We define dynamics as any change in the structure or state of a system over time. The dynamic behavior of system requires time dependent, causal relationships between the parts of the system, and feedback relations within the system. Dynamics thus means that system changes over time and exercises self-regulation generated by feedback.

\subsection{Perceived importance of IT}

The resource-based view of an organization considers each organization unique [e.g. 3, 57]. An organization is equivalent to the broad set of tangible and intangible assets, resources and capabilities that it owns semipermanently or permanently. The organization's assets, resources and capabilities as a whole, and especially imperfectly mobile, imitable and substitutable assets, resources and capabilities, determine the value creation potential of the organization [3]. The findings of prior research suggest that if IT assets, resources and capabilities are seen to have the potential to offer competitive advantages to an organization, then the organization will take actions to realize that potential $[57,48]$. Business and IT executives' education, experiences, attitudes and beliefs about the role of IT in business have been detected to influence how important IT is perceived for business and its execution [e.g. 35].

We reasoned that when an organization perceives IT as a strategic asset, resource and capability (=our definition for the concept), then the organization is likely to put more emphasis on the governance and management of IT (Section 2.2). Another likely outcome is that the organization uses more funds on IT. Thus the proportion of IT costs in percentages of revenues could be higher [7]. The perception that IT's role is significant for an organization's current and future success [39] may manifest itself also in various other concrete ways. The role of IT as a future competitive advantage could be seen to increase [3]. IT could be regarded as a partner to business [2]. IT could also be considered to have the capability to support innovations and provide value to business currently and in the future by doing that [40]. We also reasoned that the relation between the importance of IT and IT business value is dynamic. The perceived importance of IT is expected to influence IT business value positively, and higher IT business value is expected to increase the perceived importance of IT.

\subsection{Governance and management of IT}

We proposed above that the perceived importance of IT impacts IT management positively. Our reasoning is that IT is governed and managed better, when executives perceive IT important for business execution. In this text, we mainly use the shorter IT management term for this concept. Strategic management of IT is usually called (corporate) governance of IT, and is defined to be the responsibility of an organization's governance body [28], e.g., board and/or executive committee members.

Since we see the implementation of IT governance, such as the allocation of IT accountabilities between business and IT executives, as a part of business - IT alignment (Section 2.4.2.), it is necessary to distinguish the two aspects of IT governance; the strategic IT management responsibilities and activities of the governance body, and (IT) governance implementation. Governance of IT means the extension of corporate governance to IT $[55,28]$. Corporate governance refers to contractual arrangements, through which the suppliers of funds assure returns on their investments [49]. In real life, the uncertainties of organizations' environments limit the contractual nature of governance. Therefore the investors and the management agree objectives, processes, tools, rules and control principles and practices that constitute the corporate - and the IT governance arrangement that then guide (IT) governance implementation and IT management. Business and IT strategies, and other comparable documents, with their objectives and implementation plan(s) can be regarded as this contract [49]. They also constitute the basis for the alignment of business and IT activities (Section 2.4.2.).

In addition to the works cited above, our research builds also on Henderson and Venkatraman [24], Boynton et al. [6], Weill and Ross [55], Van Grembergen and DeHaes [53] and Petter et al. [42]. These studies depict what needs to be managed in IT, how IT management decisions and actions should be taken, and with what measures the outcomes of IT management should be evaluated. With IT management we understand the above listed strategic IT management issues, see also appendix 1. We reason that well managed IT impacts positively technology usage (section 2.3 ), fit (section 2.4.1.) and business-IT alignment (section 2.4.2.). The first proposition implies that good IT management results in clearer and more business justified objectives for technology usage and in better integrations between various technologies. The second,

Page 5137 
fit-related proposition, reflects reasoning according to which IT investments and developments are likely to be continued unless they show poor results and need corrective actions, or unless there are compelling business reasons to cut down IT expenditures to increase the fit to the environment. The final proposition suggests that better IT management leads to improved businessIT alignment due to the better understanding of daily IT management and IT governance implementation needs.

\subsection{Technology usage}

Above we proposed that good IT management favorably affects technology usage, since technology usage has clearer and better business justified objectives. Practitioners might claim that technology usage is the most important explaining factor for IT business value. Although this claim receives some support from prior research and may appear intuitively reasonable, the relative importance of the technology usage factor needs clearer empirical validation. We hypothesize that technology usage influences IT business value positively.

Technology usage is a challenging theoretical concept. We reason that legacy (old) technologies have already delivered most of their business value, whereas this has not happened to the same extent with new technologies [10]. It may also be easier to adjust the use volume of legacy technologies and improve the fit to the environment as compared to new technologies [4]. We reasoned that an organization knows better how to modify the use volume of legacy technologies and is able to increase the value of legacy technologies through user training, data quality and other improvements. Another challenge with new technologies, especially in multi-year studies, is to determine what technologies to include. By definition a new technology cannot be legacy. At the same time, technology adoption needs time to reach the sufficient penetration level against which business and IT executives are able to evaluate technology usage on the basis of real personal and organizational experiences.

For these reasons technologies included under the concept technology usage were e-business [e.g. 14] social media [e.g. 37], cloud services [e.g. 13] and bring-your-own device (BYOD) [e.g. 23]. In addition to the use of own devices, BYOD could mean the use of own applications, data and/or services such as Google's services or Skype. These four technologies had been available for years prior to 2013. Survey respondents had had lots of opportunities to consider their deployment in their organizations' business execution and to learn from own and others' experiences. We investigated technology usage by examining the existence of organizations' strategies and implementation plans for the deployment of each technology in their business, and the inclusion of each technology in an organization's IT strategy [23] and enterprise architecture [5].

\subsection{Fit and alignment}

Generally, the fit concept describes the suitability of something for a certain purpose, circumstance or context. If something fits, it has the right size, shape, character and/or other feature(s). In academic research, the level of fit is typically searched through pairs of interests, such as task-technology fit [20], personorganization fit $[34,26]$, person-group fit [56], organization-environment fit [18], user-computer fit [52] and/or through a firm's competitive strategies-IS capabilities fit [38]. In ITBV research, "alignment" and "fit" concepts have been conceptually so close that a few of studies have treated them as synonyms [36, 25, 27].

We distinguish fit and alignment concepts, since we see that they reflect responses to different organizational phenomena. We define fit as the degree of compatibility between IT and the external environment of an organization in line with [15]. We reason, that an organization's business specifics (=business requirements) cannot be ignored, when the fit between IT and the organization's environment (context) is considered [15]. Business specifics moderate this relationship. Similarly, we define that alignment depicts the degree of an organization's internal compatibility between IT and business. Figure 1 illustrates the difference between the fit and alignment concepts.

The duty of IT management is to make adaptive adjustments to IT structures and processes [53] to adapt them to the changes in an organization's environment. Our proposal is that IT and organizational environment need to fit together for IT to perform successfully. In our

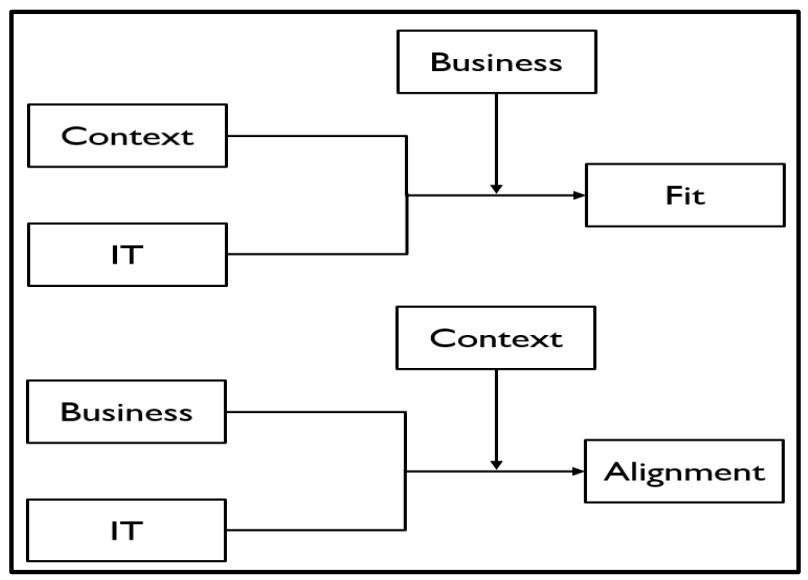

Figure 1. How fit and alignment concepts differ

research, the fit between IT and organizational environment is assessed indirectly. The survey responses of the empirical data measure the level of responsive actions taken in IT as reactions to the changes in the organizational environment, especially changes in the economy. Fit is deemed higher with more responsive and consistent actions taken.

\subsubsection{Fit}

Above in Section 2.2 we proposed that good IT management positively impacts fit, that is, an organization's ability to adapt to the changes in its external environment, especially economic cycles. Our reasoning is that, if IT is managed well, then the organization is better prepared to act consistently regarding the development and deployment of IT, when 
the economic environment of the organization changes. Consequently, we reasoned that better fit influences positively IT business value.

The data collection of this research occurred during an economic recession that continued during all the three years of data collection. Our idea to introduce the fit concept to the ITBV research emerged as our answer to questions: how do organizations adjust their IT investments, expenditures and development activities to economic cycles? What actions do IT management initiate to cope with changing economic cycles?

We reasoned that an economic recession may create pressures to intensify IT investments and developments to create new business, or, more likely, to trigger postponements, run/cut-downs and discontinuations of IT investments and developments in existing (and new) business. In concrete terms, there could thus be two complimentary approaches to increase the fit during an economic recession [4]. Firstly, an organization may cut down IT costs [11], postpose IT investments [32] and other IT developments in order to increase the costefficiency of the organization. The organization may also change its (IT) investment behavior by preferring shortreturn times on investments combined with low-level risks and/or by focusing (IT) investments into (new) businesses [40] that are believed to be important for the organization's future. Secondly, fit could be increased by improving the quality of data [51] by educating users to deploy IT better [40], by developing IT management capabilities [2], or by standardizing and consolidating IT to reduce the complexity of IT and to remove overlapping IT assets through architecture work [43]. At least a part of the latter activities could be implemented with no or little costs by utilizing available resources.

\subsubsection{Business-IT alignment}

Above, in Section 2.2, we proposed that good IT management favorably impacts business-IT alignment since the latter is one of the activities, which makes IT governance operative. Henderson and Venkatraman [24] proposed that business-IT alignment has two levels: strategic and operational. They called the former "strategic fit" and the latter "operational integration." The proposition that on strategic and operative levels well-aligned business and IT positively influence IT success is not only intuitively sound but receives also strong support from empirical research. Business-IT alignment research shows consistently that the quality of alignment has positive impacts on IT business value, that is, on organizational performance $[55,12,53]$. If the quality of alignment is high, then the organization knows better how IT impacts its business operations [55, 42].

In line with Henderson and Venkatraman we divided business-IT alignment into strategic and operational levels. We reasoned that on the strategic level wellaligned means that senior executives, other business executives and IT executives have agreed the behavioral accountabilities of IT management, IT processes and IT decisions [55]. In other words, the organization has implemented a clearly defined IT governance arrangement, which cascades top-down from the highest organizational level to unit, process and task levels, and includes both IT development and IT operations [53, 28]. On the operational level, this means that ITinfrastructure, applications, data, and processes create a well-integrated whole [51] and that the organization has reliable measures on how IT impacts its business [42].

\subsection{IT business value and its surrogates}

It is always difficult, if not impossible, to isolate the business value contributions of IT from other contributions. Therefore various surrogate measures have been used to investigate IT business value [e.g. 30, 48, 50]. Instead of user satisfaction, user acceptance, IS usage, or other similar individual and/or IS level measures, we decided to use IT project performance and overall IT satisfaction as the surrogate of IT business value to cover the value of both IT development and IT operations. One of the motivating reasons was that IT projects have relatively established success measures. We were able to use the measures of IT project success and performance research $[41,35]$ to address the development related business value of IT.

In addition to the project-oriented measures, we used an overall IT satisfaction measure to assess the general level of satisfaction on the deployment of IT within an organization. This was done to measure the business value of IT operations by linking our study to IT user satisfaction [1,10] and IS success studies [42]. We investigated IT business value at the level of an organization.

\section{Research model and methodology}

\subsection{Research model and hypotheses}

Figure 2 shows the research model used in this study. The model builds on the theoretical concepts discussed in Section 2. They are transformed into six main constructs. The research model hypothesizes that there is a relatively complex structure of direct and indirect relationships behind IT business value. We propose that IT business value is not solely dependent on technology usage, fit, or business-IT alignment. The outcomes of the model are the right combination of these constructs and the two antecedents to them, namely the governance and management (of IT) and the perceived importance of IT. The model also describes the proposed feedback between the perceived importance of IT and IT business value. The hypotheses of this research are as follows:

H1: Perceived importance of IT positively affects the governance and management of IT.

H2: Governance and management of IT positively affects technology usage.

H3: Governance and management of IT positively affects fit.

H4: Governance and management of IT positively affects business-IT alignment.

H5: Technology usage positively affects IT business value.

H6: Fit positively affects IT business value. 
H7: Business-IT alignment positively affects IT business value.

As a supplementary dynamics hypothesis, we propose that the perceived importance of IT in turn depends on the IT business value.

H8: IT business value positively affects the perceived importance of IT.

One may notice that hypotheses 1-7 are expected to have positive effects, direct or indirect, on IT business value. One may also notice that we use the full name, governance and management (of IT), for this construct.

\subsection{Research method}

To validate the research model and the hypotheses, we adopted survey research as the data collection method. In our study, we used a relatively large existing data set called IT-Barometer Data from the years 2013, 2014 and 2015. A National Data Processing Association collected the data each year with an annual survey during May and June. The data was collected with a stratified random sampling from business and IT executives, mainly from organizations with over 500 employees. We used only that part of the available data that concentrated on the hypothesized issues with a similar set of variables (survey items). Such new technologies, e.g., big data and robotics, which were added to the annual survey during the three-year period, were excluded since the data did not cover all three years. The number of measurement items per construct varied between three and eleven.

Invitation to participate to the survey along with one reminder was sent to approximately 2,000 business or IT executives each year. For example, in 2013 the invitation was sent to 2,128 persons. The invitation and the reminder generated 212 responses. Correspondingly 249 and 181 responses were received in 2014 and 2015. Thus the cumulative number of responses was 642 and the annual response rate around $10 \%$, which we regard as normal or above normal for surveys submitted to executives. Of the respondents, $47 \%(n=286)$ were CIOs and other IT executives, $35 \%(n=214)$ were business executives, and $18 \% \quad(n=111)$ were senior business experts. Six respondents did not disclose their organizational status. Twenty-eight percent of them worked in industry, $12 \%$ in commerce, $47 \%$ in services, and $13 \%$ in public sector organizations. A PLS-model was created to evaluate the measurement quality and to verify the structural hypotheses of the research model.

\section{Analysis and results}

We adopted a two-step analysis, in which the measurement model and the structural model were validated separately, and the differences between the three years were analyzed. In the analyses, we used SmartPLS (v. 3.2.6) [45].

\subsection{Measurement model}

Initially the constructs of the full model included from three to eleven indicators (survey items). First, the reliability of the full PLS model for the year 2013 was analyzed with all indicators. It soon became evident that both the reliability of some constructs (composite

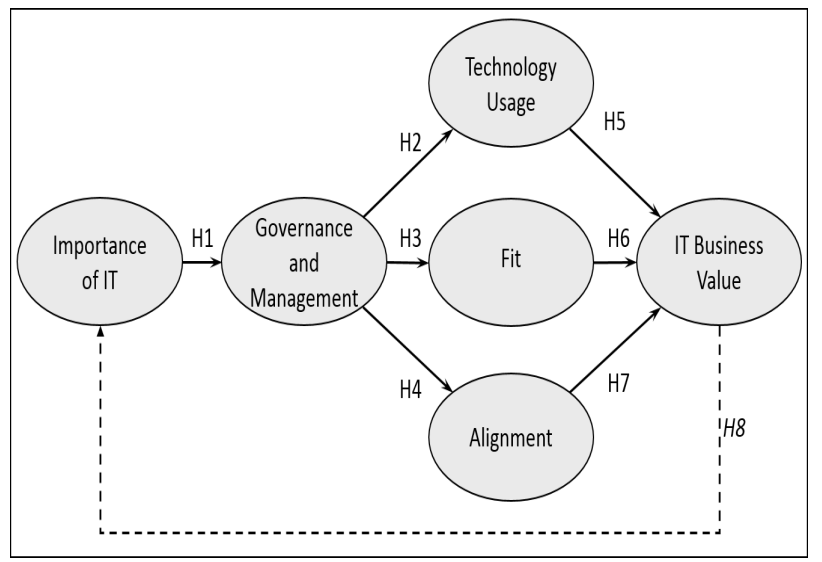

Figure 2. Research model

reliability) and their average variances extracted (AVE) were too low. We had to modify the original model. To do this, we excluded some badly behaving indicators behind the latent constructs from the model. The indicators' cross-loadings for the full PLS model were used to identify proper indicator candidates for exclusion. Data for the year 2014 was analyzed next by using the remaining indicators. Again some indicators had to be excluded from the model for the same reasons. Finally, the same process with the remaining indicators was repeated for the year 2015. The quality indicators of the final model are summarized in Table 1. Please, note that we first discussed and depicted theoretical ITBV research concepts in Section 2. We then discussed them as model constructs with the full set of indicators that together constitute the initial research model. Statistical testing was used to create the final research model.

In the determination of indicator reliability, we discovered that all squared outer loadings were above the minimum acceptable level of 0.40 [58], which indicated satisfactory reliability levels. Because all AVE and composite reliability values were greater than the recommended threshold values 0.50 and 0.70 [21], the variance caused by error terms no longer gave reasons to doubt the validity of the model, and the analysis of the measurement model suggested acceptable convergent validity. Because Cronbach's alpha assumes that all indicators are equally reliable [22] and because it provides rather conservative values in PLS-analyses [58], Cronbach's alpha is not considered suitable for PLS [58], and was omitted from the analyses.

The discriminant validity of the constructs was first evaluated by checking the indicators' cross loadings. This revealed that no indicator loaded higher on any other construct than on the "right" construct. Secondly, we used the Fornell and Larcker's [17] test to evaluate the discriminant validity further. Their test requires that the square root of the AVE for each construct should be higher than the correlations between the construct and all other constructs. Bolded diagonal elements in Table 2 are the square roots of AVE and off-diagonal elements are inter-construct correlations. Because the bolded elements in the diagonals have greater values than the elements in respective rows or columns, the results

Page 5140 
indicate that each particular construct differs every year from all other constructs. The multicollinearity of the model's latent constructs was also analyzed. The highest variance inflation factor (VIF) was 1.56, which is clearly below the critical cut-off value of 10 [31]. Thus, there is no significant multicollinearity in the model.

Table 1. Outer model assessment $\left(\mathrm{L}^{2}=\right.$ Outer Loadings ${ }^{2}$, AVE=Average Variance Extracted, CR=Composite Reliability)

\begin{tabular}{|c|c|c|c|c|c|c|c|c|c|c|}
\hline \multirow[b]{2}{*}{ Construct } & \multirow[b]{2}{*}{ Item } & \multicolumn{3}{|c|}{$2013(\mathrm{~N}=212)$} & \multicolumn{3}{|c|}{$2014(\mathrm{~N}=249)$} & \multicolumn{3}{|c|}{$2015(\mathrm{~N}=181)$} \\
\hline & & $L^{2}$ & AVE & CR & $\mathrm{L}^{2}$ & AVE & CR & $L^{2}$ & AVE & CR \\
\hline \multirow{3}{*}{ Alignment } & X41 & 0,602 & \multirow{3}{*}{0,661} & \multirow{3}{*}{0,853} & 0,658 & \multirow{3}{*}{0,607} & \multirow{3}{*}{0,823} & 0,588 & \multirow{3}{*}{0.625} & \multirow{3}{*}{0.833} \\
\hline & $\mathrm{X} 42$ & 0,791 & & & 0,594 & & & 0,634 & & \\
\hline & X43 & 0,589 & & & 0,570 & & & 0,653 & & \\
\hline \multirow{4}{*}{ Fit } & $\mathrm{X} 54$ & 0,570 & \multirow{4}{*}{0,658} & \multirow{4}{*}{0,885} & 0,581 & \multirow{4}{*}{0,626} & \multirow{4}{*}{0,870} & 0,523 & \multirow{4}{*}{0.633} & \multirow{4}{*}{0.873} \\
\hline & X55 & 0,722 & & & 0,643 & & & 0,711 & & \\
\hline & X56 & 0,618 & & & 0,629 & & & 0,630 & & \\
\hline & $\times 57$ & 0,720 & & & 0,654 & & & 0,667 & & \\
\hline \multirow{3}{*}{$G \& M$} & X31 & 0,772 & \multirow{3}{*}{0,686} & \multirow{3}{*}{0,867} & 0,746 & \multirow{3}{*}{0,642} & \multirow{3}{*}{0,843} & 0,767 & \multirow{3}{*}{0.646} & \multirow{3}{*}{0.843} \\
\hline & X32 & 0,555 & & & 0,491 & & & 0,433 & & \\
\hline & X33 & 0,732 & & & 0,692 & & & 0,738 & & \\
\hline \multirow{4}{*}{ Importance } & $\mathrm{X} 11$ & 0,534 & \multirow{4}{*}{0,619} & \multirow{4}{*}{0,866} & 0,471 & \multirow{4}{*}{0,632} & \multirow{4}{*}{0,872} & 0,591 & \multirow{4}{*}{0.622} & \\
\hline & $\mathrm{X} 12$ & 0,595 & & & 0,618 & & & 0,629 & & 088 \\
\hline & $\mathrm{X} 13$ & 0,745 & & & 0,726 & & & 0,711 & & 0.000 \\
\hline & $\mathrm{X} 14$ & 0,602 & & & 0,712 & & & 0,560 & & \\
\hline & $\mathrm{P} 1$ & 0,739 & & & 0,634 & & & 0,743 & & \\
\hline & $\mathrm{P} 2$ & 0,561 & & & 0,607 & & & 0,531 & & \\
\hline value & P3 & 0,519 & 0,598 & 0,880 & 0,740 & 0,610 & 0,886 & 0,572 & 0.607 & 0.884 \\
\hline & P4 & 0,711 & & & 0,402 & & & 0,699 & & \\
\hline & $\mathrm{Y} 1$ & 0,458 & & & 0,666 & & & 0,487 & & \\
\hline & $\times 25$ & 0,534 & & & 0,635 & & & 0,542 & & \\
\hline Usage & $\times 27$ & 0,707 & 0,594 & 0,814 & 0,607 & 0,607 & 0,822 & 0,792 & 0.708 & 0.879 \\
\hline & $\times 210$ & 0,539 & & & 0,579 & & & 0,790 & & \\
\hline
\end{tabular}

Next, we applied Multi-Group-Analysis (MGA) [46] to reveal possible differences in path coefficients between years 2013, 2014 and 2015. The null hypothesis is that the path coefficients are equal across all years. Table 3 shows the absolute values of the differences in path coefficients (2013 vs. 2014, 2013 vs. 2015, and 2014 vs. 2015) with respective t-test values. Generally, and consistent with the outer loadings, there were no systematic statistically significant differences in path coefficients between the years.

There were a few statistically significant differences in the validity measures of the constructs between years. In Table 3, the differences in the AVE and the composite reliability values of technology usage are statistically significant between years 2013 and 2015 as well as between the years 2014 and 2015 . Other 34 differences in the validity measures are statistically not significant. In summary, since the annual PLS models were firmly backed up by reliability and validity statements, the assessment of the structural model and the respective hypotheses could be conducted to answer the research questions of the study.

\subsection{Structural model}

After the refinement and validation of the measurement model, we proceeded to test the hypotheses of the research model by assessing the structural (inner) model. A nonparametric bootstrapping procedure was used to detect the significance of all path coefficients and the estimates for the standard errors within the research model [47]. Bootstrapping procedures with 212, 249, and 181 cases for the years 2013, 2014, and 2015, respectively, and 5000 resamples were used to test our hypotheses. The results of the analyses are summarized in Figure 3 and Appendix 2, which discloses the yearly coefficients with their overall trends, the explained variances $\left(\mathrm{R}^{2}\right)$, the direct, indirect, and total effects, and the respective significance levels of t-tests. The total effects are calculated by summing up the direct and indirect effects as shown by Sattler et al. [47]. The analyses indicate that hypotheses $\mathrm{H} 1, \mathrm{H} 2, \mathrm{H} 3, \mathrm{H} 4$, and $\mathrm{H} 7$ were supported for all the three years. Hypothesis H5 (technology usage impacts positively ITBV) was not supported for any of the years and hypothesis H6 (fit impacts ITBV) not for the year 2015. In summary, the results of hypothesis testing and $\mathrm{R}^{2}$ values suggest that the proposed model has good explanatory power.

In addition to the direct effects, there were significant indirect effects: the perceived importance of IT had significant effects on IT governance and management, fit, technology usage, and IT business value in every year. In addition, the "goodness" of IT governance and management had significant indirect effect on IT business value. As Figure 3 shows, the biggest differences in $\mathrm{R}^{2}$ are in alignment and in governance \& management (2013 vs. 2014). In summary, the research model appears to be fairly stable over the investigated three-year period in addition to good explanatory power.

Next, the supplementary analysis on the feedback effect from IT business value to the perceived importance of IT (Hypothesis H8) was conducted. Because of the statistical method we used (PLS), we had to remove the connection from IT importance to IT management and governance from the model and add the

Table 2. Discriminant validity assessments, Fornell-Lacker's test

\begin{tabular}{|c|c|c|c|c|c|c|c|c|c|c|c|c|c|c|c|c|c|c|}
\hline & \multicolumn{6}{|c|}{2013} & \multicolumn{6}{|c|}{2014} & \multicolumn{6}{|c|}{2015} \\
\hline & A & $\mathbf{F}$ & GM & I & BV & TU & A & $\mathbf{F}$ & GM & I & BV & TU & A & $\mathbf{F}$ & GM & I & BV & TU \\
\hline Alignment, A & ,81 & & & & & & ,78 & & & & & & ,79 & & & & & \\
\hline Fit, F &, 50 & ,81 & & & & & ,57 & 79 & & & & & ,35 & ,80 & & & & \\
\hline$G \& M, G M$ & ,56 &, 58 & ,83 & & & & 67 & ,58 & ,80 & & & & 64 & ,57 & 80 & & & \\
\hline Importance, I & ,51 &, 50 & ,72 & 79 & & & ,39 & ,48 & ,64 & ,80 & & & ,39 & ,56 & ,67 & ,79 & & \\
\hline ITBV, BV & 62 & 48 & ,48 & ,54 & ,77 & & ,56 & ,47 & ,51 & ,38 & 78 & & 60 & ,27 & 47 & ,34 & ,78 & \\
\hline Technology Usage, TU & ,36 & ,31 & ,42 & ,38 & ,34 & ,77 & ,39 & ,38 & ,46 & ,20 & ,29 & ,78 & ,57 & ,31 & ,49 & , & e, 424 & 1,84 \\
\hline
\end{tabular}


connection from IT business value to the perceived importance of IT for this analysis. Hypothesis H8 (feed- depends on the value that IT delivers to business. In summary, the results of our research indicate that "good"

Table 3. Multi-group comparison of path coefficients and t-test values for years 2013-2015 IT management has a

\begin{tabular}{|c|c|c|c|c|c|c|}
\hline & $\begin{array}{c}\mid \operatorname{diff}(2013 \\
-2014) \mid\end{array}$ & \begin{tabular}{|c|}
$t-v a l u e$ \\
$\mid$ diff (2013- \\
$2014) \mid$ \\
\end{tabular} & $\begin{array}{c}\text { diff } \\
(2013- \\
2015) \mid \\
\end{array}$ & \begin{tabular}{|c|} 
t-value \\
$\mid$ diff (2013- \\
$2015) \mid$ \\
\end{tabular} & $\begin{array}{c}\text { diff } \\
(2014- \\
2015) \mid \\
\end{array}$ & \begin{tabular}{|c} 
t-value \\
|diff (2014- \\
$2015) \mid$ \\
\end{tabular} \\
\hline Alignment $\rightarrow$ ITBV & 0,055 & 0,619 & 0,045 & 0,498 & 0,100 & 1,078 \\
\hline Fit $\rightarrow$ ITBV & 0,009 & 0,090 & 0,152 & 1,436 & 0,161 & 1,543 \\
\hline$G \& M \rightarrow$ Alignment & 0,111 & 1,786 & 0,077 & 1,017 & 0,035 & 0,545 \\
\hline G \& M $\rightarrow$ Fit & 0,000 & 0,002 & 0,008 & 0,096 & 0,008 & 0,096 \\
\hline G \& M $\rightarrow$ Technology Usage & 0,035 & 0,438 & 0,064 & 0,708 & 0,029 & 0,369 \\
\hline Importance $\rightarrow$ G \& M & 0,080 & 1,354 & 0,044 & 0,746 & 0,036 & 0,540 \\
\hline Technology Usage $\rightarrow$ ITBV & 0,059 & 0,697 & 0,002 & 0,021 & 0,061 & 0,636 \\
\hline
\end{tabular}

key role in the achievement of IT business value, and that executives' perceptions that IT is significant for business influences positively how "good" IT management is. This is our response to the first research question.

We built and tested a theoretical model with

back effect) received strong statistical supported for all the three years. The path coefficients of the feedback relation are shown in Figure 3 and the respective $R^{2}$ s for the three years were $0.29,0.17$, and 0.21 . They are not shown in Figure 3 due to limited space. This expected result confirmed our proposal that IT management is a dynamic, and at least partly self-regulating process.

\section{Discussion and conclusions}

The main objective of this research was to explore the role of IT management as the enabler of IT business value. We discovered that IT management was a highly significant determinant for ITBV. More importantly, the influence of IT management was path-mediated by three dynamic paths: IT usage, fit (to the environment), and especially business-IT alignment. We also discovered that the perceived importance of IT to an organization's business is a significant antecedent to IT management. In addition, there was a significant feedback-relation from IT business value to the perceived importance of IT. This indicates that the perceived importance of IT heavily eight hypotheses after reviewing IT Business Value Research to find suitable concepts to be used as research model constructs. In literature review, we discussed five extensively studied concepts and added the less investigated fit concept to the ITBV research. We found that the constructs of the model separately and as a whole were good predictors for IT business value. More specifically, six of the hypotheses were supported every year, one during two years and the remaining hypothesis not at all. This is our answer to the second research question.

We discovered that IT management was a significant determinant to fit (to organizational environment). Fit impacted positively IT business value for the years 2013 and 2014 but not for the year 2015. The why question is relevant, especially since there is a significant difference between the year 2015 on one had side and the years 2013 and 2014 on the other hand side. Although this could be a model and data idiosyncrasy, a logical explanation is also possible. The economic recession had continued during the entire three-year period. Thus, it is possible that organizations reacted immediately to the

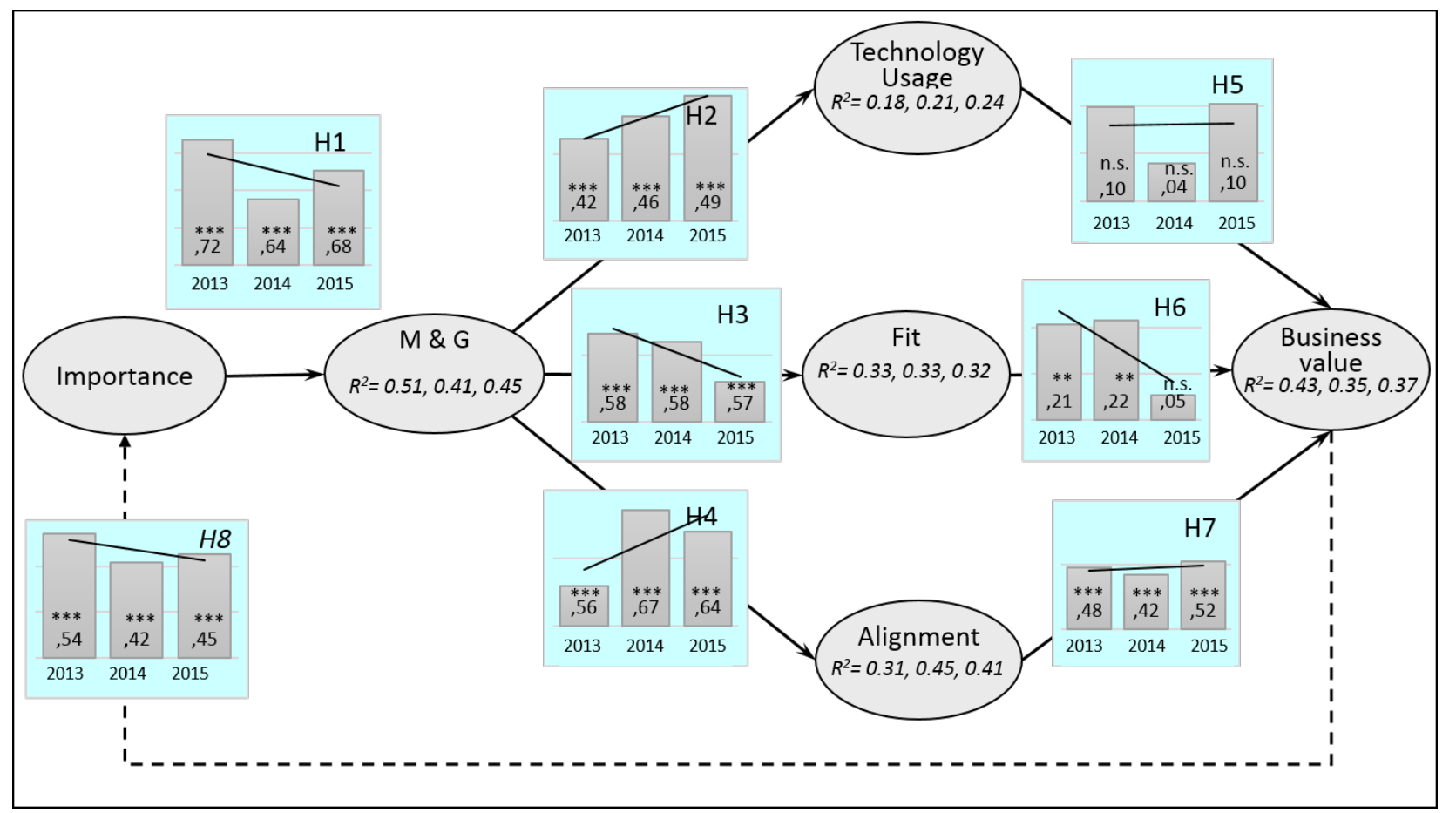

Figure 3. Direct path coefficients and $R^{2}$ for $2013-2015$, original sample 
changed environment during the first two years but no more after the recession had continued for a long time. A future study could investigate how rapidly changes in the economic environment lead to responses in IT investments and in IT expenditure behavior.

It was a surprise to us that technology usage was not a significant determinant for IT business value. Moreover, the initial model had 11 indicators, out of which only 3 behaved consistently and were included in the final model. The technology usage indicators behaved thus in different ways. For example, if a respondent indicated that her/his organization had a clear strategy for the use of cloud services in business (s)he could respond in any way to the same questions regarding the three other technologies. This appears to implicate that organizations manage new technologies in isolation instead of a holistic approach. We calculated how many respondents indicated strongly that their organization had a clear strategy to all four technologies. In 2015, as an example, 8 persons out of 181 respondents answered in this way. This is a highly interesting issue for future research.

Although our research was able to explain a large proportion of IT business value $\left(\mathrm{R}^{2}=0.43,0.35\right.$, and $0.37)$, the constructs of our model do not represent a complete set of possible constructs that impact IT business value. For example, we were forced to leave out the impact of business and IT executives' (IT] competencies. On the other hand, respondent's industry, size of organization, career in either business or IT, CIO's presence in an organization's executive committee, CIO's reporting relationship, the inclusion business IT costs in addition to "traditional" IT costs had limited amount of dependencies with the survey items shown in Appendix 1, as analyzed with t-test.

Because it is difficult to isolate the impacts of IT from other factors' impacts on organizational performance, we had to use surrogate measures for IT business value. This and the reliance on one-country data are the most serious limitations of our research. Other multi-year survey data sets collected from business and IT executives with random sampling were not identified or available.

Our recommendation to practitioners, especially to business executives, is to ensure that they understand and agree as individuals and collectively the business significance of information technologies the business of their organization. On the basis of such understanding they are better able to manage and govern IT, and through IT management to guide the usage of technology, to adjust IT to the organization's environment, to align business and IT, and to increase IT business value.

\section{References}

[1] Aladwani, A.M. Organizational Actions, Computer Attitudes, and End-User Satisfaction in Public Organizations: An Empirical Study. Journal of End User Computing, 14, 1 (2002), 42-49.

[2] Aral, S. and Weill, P. IT Assets, Organizational Capabilities, and Firm Performance: How Resource Allocations and Organizational Differences Explain Performance Variation. Organization Science, 18, 5 (2007), 763-780.
[3] Barney, J.B. Firm Resources and Sustained Competitive Advantage. Journal of Management, 17, 1 (1991), 109-120.

[4] Bergeron, F., Raymond, L. and Rivard, S. Fit in Strategic Information Technology Management Research: An Empirical Comparison of Perspectives. Omega, 292 (2001), 125-142.

[5] Boh, W.F. and Yellin, D. Using Enterprise Architecture Standards in Managing Information Technology. Journal of Management Information Systems, 233 2006), 163-207.

[6] Boynton, A.C., Zmud, R.W. and Jacobs, G.C. The Influence of IT Management Practice on IT Use in Large Organizations. MIS Quarterly, 18, 3 (1994), 299-318.

[7] Brynjolfsson, E., and Brown, P. VII pillars of IT Productivity. Optimize, 4, 5 (2005), 26-35.

[8] Brynjolfsson, E., and Hitt, L.M. Beyond the Productivity Paradox. Communications of the ACM, 41, 8 (1998), 49-55.

[9] Carr, N.G. (2003). IT Doesn't Matter. Harvard Business Review. 81(5), 5-12.

[10] Cecez-Kecmanovic, D., Kautz, K. and Abrahall, R. Reframing Success and Failure of Information Systems: A Performative Perspective. MIS Quarterly, 382 (2014). 561588.

[11] Cha, H.S., Pingry, D.E. and Thatcher, M.E. What determines IT spending priorities? Communications of the ACM, 52, 8 (2009), 105-110.

[12] Chan, Y. and Reich, B. IT Alignment: What Have We Learned? Journal of Information Technology, 22, 4 (2007), 297-315.

[13] Choudhary, V. and Vithayathil, J. The Impact of Cloud Computing: Should the IT Department Be Organized as a Cost Center or a Profit Center? Journal of Management Information Systems, 30 2, (2013), 67-100.

[14] Coltman, T.R., Devinney, T.M.and Midgley, D.F. EBusiness Strategy and Firm Performance: A Latent Class Assessment of the Drivers and Impediments to Success. Journal of Information Technology, 22, 2 (2007), 87-101.

[15] Drazin, R. and Van de Ven. A.H. Alternative Forms of Fit in Contingency Theory. Administrative Science Quarterly, 30, 4 (1985), 514-539.

[16] Drnevich, P.L., and Croson, D.C. Information Technology and Business-Level Strategy: Toward an Integrated Theoretical Perspective. MIS Quarterly, 37, 2 (2013), 484-509.

[17] Fornell, C., and Larcker, D. F. Evaluating structural equation models with unobservable variables and measurement error. Journal of Marketing Research, 18, 1 (1981), 39-50.

[18] Gabarro, J.J. Diagnosing Organization-Environment "Fit": Implications for Organization Development. Education and Urban Society, 6, 2 (1974), 153-178.

[19] Goh, K.H., and Kauffman, R.J. Firm Strategy and the Internet in U.S. Commercial Banking. Journal of Management Information Systems, 30, 2 (2013), 9-40.

[20] Goodhue, D.L. and Thompson, R.L. Task-technology fit and individual performance. MIS Quarterly, 19, 2 (1995), 213236.

[21] Hair, J.F., Ringle, C.M. and Sarstedt, M. PLS_SEM: Indeed a Silver Bullet. Journal of Marketing Theory and Practice, 19, 2 (2011), 139-151.

[22] Hair, J. F., Sarstedt, M., Ringle, C. M. and Mena, J. A. An assessment of the use of partial least squares structural equation modeling in marketing research. Journal of the Academy of Marketing Science, 40, 3 (2012), 414-433.

[23] Harris, J., Ives, B. and Junglas, I. IT Consumerization: When Gadgets Turn Into Enterprise IT Tools. MIS Quarterly Executive, 11, 3 (2012), 90-112. 
[24] Henderson, J.C. and Venkatraman, N. Strategic Alignment: Leveraging Information Technology for Transforming Organizations. IBM Systems Journal, 32, 1 (1993), 4-16.

[25] Hirschheim, P., and Sabherwal, R. Detours in the Path toward Strategic Information Systems Alignment. California Management Review, 44, 1 (2001), 87-108.

[26] Hoffman, B.J., and Woehr, D.J. A quantitative review of the relationship between person-organization fit and behavioral outcomes. Journal of Vocational Behavior, 68, 3 (2006), 389399.

[27] Hussin, H., King, M. and Cragg, P. IT alignment in small firms, European Journal of Information Systems. 11, 2 (2002), $108-127$.

[28] International Organization for Standardization, ISO/IEC 35800:2008 Corporate Governance of Information Technology, International Standard. International Organization for Standardization and the International Electrotechnical Commission. (2008), Downloaded from http://www.iso.org.

[29] Kearns, G. and Sabherwal, R. Strategic Alignment between Business and Information Technology: a KnowledgeBased View of Behaviors, Outcome, and Consequences. Journal of Management Information Systems, 23, 1 (2007), 129-162.

[30] Keen, P.G.W. MIS research: Reference disciplines and a cumulative tradition, ICIS 1980 Proceedings, (1980). 9 p.

[31] Kleinbaum, L., Kupper, L., and Muller, K.E. Applied regression analysis and other multivariate methods, (1988), 2nd ed. Boston, MA: PWS-Kent

[32] Kohli, R., Devaraj, S. and Ow, T.T. Does Information Technology Investment Influence a Firm's market Value? A Case of Non-Publicly Traded Healthcare Firms. MIS Quarterly, 36, 4 (2012), 1145-1163.

[33] Kohli, R. and Grover, V. Business Value of IT: An Essay on Expanding Research Directions to Keep up with the Times. Journal of the Association for Information Systems, 9, 1 (2008), 23-39.

[34] Kristof, A.L. Person-organization fit: An integrative review of its conceptualizations, measurement, and implications. Personnel Psychology, 49, 1 (1996), 1-49.

[35] Liu, S., Zhang, J., Keil, M., and Chen, T. Comparing Senior Executive and Project Manager Perceptions of IT Project Risk: A Chinese Delphi Study. Information Systems Journal, 20, 4 (2010), 319-355.

[36] Luftman, J.N., Lewis P.R.. and Oldach, S.H. Transforming the Enterprise: The Alignment of Business and Information Technology Strategies. IBM Systems Journal, 32, 1 (1993), 198-221.

[37] Luo, X. and Zhang, J. How Do Consumer Buzz and Traffic in Social Media Marketing Predict the Value of the Firm? Journal of Management Information Systems, 30, 2 (2013), 213-238.

[38] McLaren, T. S., Head, M.M., Yuan, Y. and Chan, Y.E. A Multilevel Model for Measuring Fit between a Firm's Competitive Strategies and Information Systems Capabilities. MIS Quarterly, 35, 4 (2011), 909-A10.

[39] Melville, N., Kraemer, K. and Gurbaxani, V. Information Technology and Organizational Performance: An Integrative Model of IT Business Value. MIS Quarterly, 28, 2 (2004), 283-322.

[40] Mithas, S., Ramasubbu, N. and Sambamurthy, V. How Information Management Capability Influences Firm Performance. MIS Quarterly, 35, 1 (2011), 237-256.
[41] Nelson, R.R. IT Project Management: Infamous Failures, Classic Mistakes, and Best Practices. MIS Quarterly Executive, 6, 2 (2007). 163-183.

[42] Petter, S., DeLone, W. and McLean, E.R. Information Systems Success: The Quest for the Independent Variables. Journal of Management Information Systems, 29, 4 (2013), 7 61.

[43] Pollalis, Y. Patterns of Co-alignment in Informationintensive Organizations: Business Performance Through Integration Strategies. International Journal of Information Management, 23, 6 (2003), 469-492.

[44] Porter, M.E. Strategy and the Internet. Harvard Business Review, 79, 3 (2001), 62-78.

[45] Ringle, C.M., Wende, S., \& Becker, J.-M.. "SmartPLS 3." Boenningstedt: SmartPLS GmbH, (2015 http://www.smartpls.com.

[46] Sarstedt, M., Henseler, J. and Ringle, C.M. Multi-group analysis in Partial Least Squares (PLS) path modeling: Alternative methods and empirical results. Advances in International Marketing, 22, 2 (2011). 195-218.

[47] Sattler, H., Völckner, F., Riediger, C., \& Ringle, C.M. The Impact of Brand Extension Success Factors on Brand Extension Price Premium. International Journal of Research in Marketing, 27, 4 (2010), 319-328.

[48] Schryen, G. Revisiting IS Business Value Research: What We Already Know, What We Still Need to Know, and How We Can Get There. European Journal of Information Systems, 22, November (2013), 139-169.

[49] Shleifer A. and Vishny R.W. A survey of Corporate Governance. Journal of Finance, 52, 2 (1997), 737-783.

[50] Straub, D.W. Validating instruments in MIS research. MIS Quarterly, 13, 2 (1989), 147-169.

[51] Tallon, P.P., Ramirez, V. and Short, J.E. The Information Artifact in IT Governance: Toward a Theory of Information Governance. Journal of Management Information Systems, 30, 3 (2013), 141-177.

[52] Te'eni, D. Designs That Fit: An Overview of Fit Conceptualizations in HCI in Zhang, P. and Galletta, D. F., (eds), Human-computer Interaction and Management Information Systems: Foundations, (2006), M.E.Sharpe, Armonk, New York.

[53] Van Grembergen, W., and De Haes, S. Implementing Information Technology Governance: Models, Practices and Cases. (2008), Idea Group Global, Hershey.

[54] Ward, P. and Zhou, H. Impact of Information Technology Integration and Lean/Just-In-Time Practices on Lead-Time Performance. Decision Sciences, 37, 2 (2006), 177203.

[55] Weill, P. and Ross, J. A Matrixed Approach to Designing IT Governance. Sloan Management Review, 40, 2 (2005), 2634.

[56] Werbel, J.D and Johnson, D.J. The use of person-group fit for employment selection: A missing link in personenvironment fit. Human Resource Management, 40, 3 (2001), 227-240.

[57] Wiengarten, F., Humphreys, P., Cao, G. and McHugh, M. Exploring the Important Role of Organizational Factors in IT Business Value: Taking a Contingency Perspective on the Resource-Based View. International Journal of Management Reviews, 15, 1 (2013), 30-463.

[58] Wong, K.K. Partial least squares structural equation modeling (PLS-SEM) techniques using SmartPLS. Marketing Bulletin, 24, 1 (2013), 1-32. 


\section{Appendix 1. Operational definitions of the measures in the final research model}

\begin{tabular}{|c|c|c|c|}
\hline Const. & \multicolumn{2}{|r|}{ Question item - Evaluate how well the following statements apply to your organization } & Reference \\
\hline \multirow{6}{*}{ 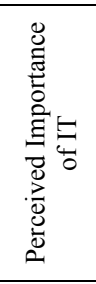 } & \multicolumn{2}{|r|}{ IT as a source of competitive advantage and improved organizational performance } & \\
\hline & $\mathrm{X} 11$ & The role of IT as a future competitive advantage increases & 3,39 \\
\hline & $\mathrm{X} 12$ & IT serves our business as a partner & $2,6,57$ \\
\hline & \multicolumn{2}{|r|}{ The capability of IT to support innovations and to provide value to business in this way } & \\
\hline & $\mathrm{X} 13$ & $\begin{array}{l}\text { IT provides value to our business by facilitating the development of new innovations and by increasing } \\
\text { the efficiency of our business processes }\end{array}$ & 6,40 \\
\hline & $\mathrm{X} 14$ & $\begin{array}{l}\text { It is extremely important to our future success that IT provide value to our business by facilitating the } \\
\text { development of new innovations and by increasing the efficiency of our business processes in the future }\end{array}$ & 40 \\
\hline \multirow{5}{*}{ 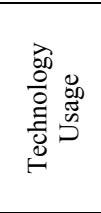 } & \multicolumn{2}{|r|}{ Strategic role and deployment of cloud services } & \\
\hline & $\mathrm{X} 25$ & My organization has a clear strategy and implementation plan for cloud services in business operations & 13 \\
\hline & \multicolumn{2}{|r|}{ Strategic role and deployment of BYOD (Bring Your Own Device)/IT consumerization } & \\
\hline & $\mathrm{X} 27$ & My organization has a clear strategy and implementation plan for BYOD in business operations & 23 \\
\hline & $\mathrm{X} 210$ & $\begin{array}{l}\text { In my organization, BYOD is acknowledged in our IT strategy and implementation plan as well as in the } \\
\text { development of IT services }\end{array}$ & 23 \\
\hline \multirow{4}{*}{ 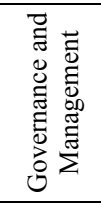 } & \multicolumn{2}{|r|}{ The strategic management of IT } & \\
\hline & $\mathrm{X} 31$ & We manage IT and develop its management as a strategic means & $6,12,29,39$ \\
\hline & $\mathrm{X} 32$ & $\begin{array}{l}\text { It is extremely important to our future success that we manage IT and develop its management as a } \\
\text { strategic means in the future }\end{array}$ & 39 \\
\hline & $\mathrm{X} 33$ & $\begin{array}{l}\text { We align the objectives of our IT activities with our business objectives so that we are able to evaluate } \\
\text { how IT impacts the achievement of our business objectives }\end{array}$ & $\begin{array}{l}12,16,24, \\
55\end{array}$ \\
\hline \multirow{5}{*}{ 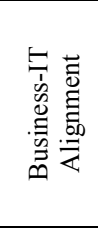 } & \multicolumn{2}{|r|}{ Operative alignment of business and IT } & \\
\hline & $\mathrm{X} 41$ & We know well the impact of IT on our business & $6,39,42$ \\
\hline & $\mathrm{X} 42$ & In our organization's IT infrastructure, applications, data, and processes create an integrated whole & 51 \\
\hline & \multicolumn{2}{|r|}{ Strategic alignment of business and IT } & \\
\hline & X43 & $\begin{array}{l}\text { Senior executives, business unit executives, and IT executives share the accountabilities and } \\
\text { responsibilities of IT management on the basis of clearly defined governance arrangement }\end{array}$ & $\begin{array}{l}12,24,51, \\
53,55\end{array}$ \\
\hline \multirow{5}{*}{ 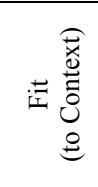 } & \multicolumn{2}{|r|}{ The impact of economy on business operations during the recent year } & \\
\hline & X54 & We increased IT benefits by educating users & 40 \\
\hline & $\mathrm{X} 55$ & We improved the quality of IT-enabled data and eliminated problems caused by broken data flows & $40,43,51$ \\
\hline & X56 & We integrated and consolidated our enterprise architecture & 5,43 \\
\hline & X57 & We improved business driven IT management within our organization & 2 \\
\hline \multirow{5}{*}{ 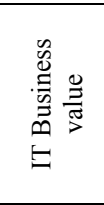 } & Y1 & $\begin{array}{l}\text { What elementary school grading (4-10) would you give to the deployment of IT as a whole within your } \\
\text { organization? }\end{array}$ & $1,10,42$ \\
\hline & \multicolumn{2}{|r|}{ Evaluate how well IT projects succeeded in your organization } & \\
\hline & P1 & The outcomes of IT projects correspond in general with our plans & 10,41 \\
\hline & $\mathrm{P} 2$ & IT projects kept their time-tables & 35,41 \\
\hline & P3 & IT projects kept their agreed budgets & 35,41 \\
\hline
\end{tabular}

\section{Appendix 2. Direct, indirect, and total effects (significant in bold)}

\begin{tabular}{|c|c|c|c|c|c|c|}
\hline Bootstrapping, 5000 subsamples & \multicolumn{2}{|c|}{2013} & \multicolumn{2}{|c|}{2014} & \multicolumn{2}{|c|}{2015} \\
\hline Direct path coefficients & $\begin{array}{c}\text { Sample } \\
\text { Mean }\end{array}$ & $\begin{array}{c}\mathrm{T} \\
\text { Statistics } \\
\end{array}$ & $\begin{array}{c}\text { Sample } \\
\text { Mean }\end{array}$ & $\begin{array}{c}\mathrm{T} \\
\text { Statistics } \\
\end{array}$ & $\begin{array}{c}\text { Sample } \\
\text { Mean }\end{array}$ & $\begin{array}{c}\mathrm{T} \\
\text { Statistics } \\
\end{array}$ \\
\hline Alignment $\rightarrow$ ITBV & 0,481 & 7,767 & 0,422 & 6,535 & $\mathbf{0 , 5 2 3}$ & 7,968 \\
\hline Fit $\rightarrow$ ITBV & 0,205 & 3,009 & 0,218 & 3,244 & 0,054 & 0,659 \\
\hline Importance $\rightarrow \mathrm{G} \& \mathrm{M}$ & 0,719 & 20,164 & 0,639 & 14,205 & 0,676 & 13,684 \\
\hline $\mathrm{G} \& \mathrm{M} \rightarrow$ Alignment & 0,562 & 10,806 & 0,673 & 18,284 & 0,639 & 11,542 \\
\hline $\mathrm{G} \& \mathrm{M} \rightarrow$ Fit & $\mathbf{0 , 5 7 9}$ & 11,662 & $\mathbf{0 , 5 8 1}$ & 12,709 & $\mathbf{0 , 5 7 3}$ & 7,946 \\
\hline $\mathrm{G} \& \mathrm{M} \rightarrow$ Technology Usage & $\mathbf{0 , 4 3 0}$ & 6,714 & 0,463 & 9,156 & $\mathbf{0 , 4 9 0}$ & 8,083 \\
\hline Technology Usage $\rightarrow$ ITBV & 0,103 & 1,775 & 0,045 & 0,638 & 0,102 & 1,324 \\
\hline \multicolumn{7}{|l|}{ Indirect effects } \\
\hline Importance $\rightarrow$ Alignment & 0,405 & 8,762 & $\mathbf{0 , 4 3 0}$ & 11,595 & $\mathbf{0 , 4 3 1}$ & 9,739 \\
\hline Importance $\rightarrow$ Fit & 0,417 & 8,743 & $\mathbf{0 , 3 7 1}$ & 8,765 & $\mathbf{0 , 3 8 8}$ & 5,988 \\
\hline Importance $\rightarrow$ ITBV & $\mathbf{0 , 3 1 3}$ & 7,736 & $\mathbf{0 , 2 7 5}$ & 8,329 & $\mathbf{0 , 2 8 3}$ & 6,148 \\
\hline Importance $\rightarrow$ Technology Usage & $\mathbf{0 , 3 1 0}$ & 5,901 & 0,295 & 8,360 & $\mathbf{0 , 3 3 1}$ & 7,555 \\
\hline $\mathrm{G} \& \mathrm{M} \rightarrow \mathrm{ITBV}$ & $\mathbf{0 , 4 3 5}$ & 9,639 & 0,431 & 10,603 & 0,418 & 7,332 \\
\hline \multicolumn{7}{|l|}{ Total effects } \\
\hline Alignment $\rightarrow$ ITBV & $\mathbf{0 , 4 8 1}$ & 7,767 & 0,422 & 6,535 & $\mathbf{0 , 5 2 3}$ & 7,968 \\
\hline Fit $\rightarrow$ ITBV & $\mathbf{0 , 2 0 5}$ & 3,009 & 0,218 & 3,244 & 0,054 & 0,659 \\
\hline Importance $\rightarrow$ Alignment & 0,405 & 8,762 & $\mathbf{0 , 4 3 0}$ & 11,595 & 0,431 & 9,739 \\
\hline Importance $\rightarrow$ Fit & 0,417 & 8,743 & $\mathbf{0 , 3 7 1}$ & 8,765 & $\mathbf{0 , 3 8 8}$ & 5,988 \\
\hline Importance $\rightarrow$ G \& M & $\mathbf{0 , 7 1 9}$ & 20,164 & 0,639 & 14,205 & 0,676 & 13,684 \\
\hline Importance $\rightarrow$ ITBV & $\mathbf{0 , 3 1 3}$ & 7,736 & 0,275 & 8,329 & 0,283 & 6,148 \\
\hline Importance $\rightarrow$ Technology Usage & $\mathbf{0 , 3 1 0}$ & 5,901 & $\mathbf{0 , 2 9 5}$ & 8,360 & $\mathbf{0 , 3 3 1}$ & 7,555 \\
\hline $\mathrm{G} \& \mathrm{M} \rightarrow$ Alignment & 0,562 & 10,806 & 0,673 & 18,284 & 0,639 & 11,542 \\
\hline $\mathrm{G} \& \mathrm{M} \rightarrow$ Fit & $\mathbf{0 , 5 7 9}$ & 11,662 & $\mathbf{0 , 5 8 1}$ & 12,709 & $\mathbf{0 , 5 7 3}$ & 7,946 \\
\hline $\mathrm{G} \& \mathrm{M} \rightarrow \mathrm{ITBV}$ & $\mathbf{0 , 4 3 5}$ & 9,639 & $\mathbf{0 , 4 3 1}$ & 10,603 & 0,418 & 7,332 \\
\hline $\mathrm{G} \& \mathrm{M} \rightarrow$ Technology Usage & $\mathbf{0 , 4 3 0}$ & 6,714 & 0,463 & 9,156 & 0,490 & 8,083 \\
\hline Technology Usage $\rightarrow$ ITBV & 0,103 & 1,775 & 0,045 & 0,638 & 0,102 & 1,324 \\
\hline
\end{tabular}

